\title{
Microscopic Morphology Observation of Fracture Healing Process Promoted by Panax Notoginseng Saponins
}

\author{
Observación Microscópica de la Morfología del Proceso de Curación \\ de Fracturas Promovida por Panax Notoginseng Saponins
}

\author{
Chen Yang ${ }^{1,2}$; Shicai Yang ${ }^{3}$; Linwei Lyu ${ }^{1,2}$; Chunqiu Zhang ${ }^{1,2} \&$ Wen Shi ${ }^{4}$
}

YANG, C.; YANG, S.; LYU, L.; ZHANG, C. \& SHI, W. Microscopic morphology observation of fracture healing process promoted by Panax Notoginseng Saponins. Int. J. Morphol., 39(6):1581-1586, 2021.

SUMMARY: The aim of this study was to explore promoting effect of external applying Panax Notoginseng Saponins (PNS) on fractures. For this analysis 18 New Zealand male rabbits were divided into control group, splintage group and PNS group. All rabbits were performed left radius fractures and natural healing, splintage healing and splintage coated with PNS healing. 2 rabbits in each group were sacrificed on day 14, day 28 and day 42 after surgery, separately. Atomic force microscope scanning and nanoindentation tests were performed on the callus sections. The particle size and roughness in PNS group was both less than that in splintage group. The elastic modulus of callus in PNS group was consistent with normal bone tissue started from day 28 after surgery, two weeks earlier than that in splintage group. PNS could significantly reduce fracture healing time and increase strength of callus.

KEY WORDS: Cortical fracture healing; PNS (Panax Notoginseng Saponins); Atomic force microscope (AFM); Nanoindentation.

\section{INTRODUCTION}

Cortical bone fracture is a common fracture, mainly occurs in the elderly with osteoporosis (Nalla et al., 2014). In clinical, the main physical therapies are external fixation (e.g., plaster fixation or splintage) and internal fixation (e.g., bone plate or intra-medullary nail) (Giannoudis et al., 2007; OsagieClouard et al., 2019; Vestergaard et al., 2020). In order to make patients rehabilitation as soon as possible, medication-assisted therapy is usually occupied after physical therapies. Panax notoginseng saponins (PNS) I soften used to relieve osteoporosis and promote osteogenesis during healing process (Huang et al., 2017). A detailed analysis of the effect of PNS on osteogenesis is of great significance for clinical treatment.

It was found that PNS could protect bone marrow stromal cells from stress induced damage to promote osteogen-esis and bone formation (Qiang et al., 2010; Li et $a l ., 2011)$.The main principle of PNS works were to stimulate the activities of alkaline phosphatase to increase the number of osteoblasts, therefore promoting the proliferation of bone marrow mesenchymal stromal cells. PNS also promoted the prolifera-tion and osteogenic differentiation of NIH 3 T3 fibroblasts by increasing phosphorylation of ERK1/2 protein kinase (Wang et al., 2016). The proliferation and osteogenic differentiation of bone marrow stromal cells were found to associate with bone healing capacity such as for cortical bone fracture (Egermann et al., 2005). All these studies suggested that PNS had the potential to increase bone healing rate and shorten patient bed time.

In addition, PNS had a significant effect to fight osteoporosis. It was revealed that PNS had the beneficial effects on bone metabolism based on indicators of bone remodeling (Shen et al., 2010). PNS was able to prevent OVX-induced decrease in BMD, bone strength, and bone micro architecture (Shen et al.). PNS treatment significantly prevented bone mass loss and microarchitecture deterioration through the reduction of marrow adipogenesis (Fan et al., 2015).

\footnotetext{
${ }^{1}$ Tianjin Key Laboratory for Advanced Mechatronic System Design and Intelligent Control, Tianjin University of Technology, Tianjin, China.

${ }^{2}$ National Demonstration Center for Experimental Mechanical and Electrical Engineering Education, Tianjin University of Technology, Tianjin, China.

${ }^{3}$ Second affiliated hospital of Tianjin university of TCM, Tianjin, China.

${ }^{4}$ Just Huajian Medical Devices (Tianjin) Co., Ltd., Tianjin, China.

Chen Yang and Shicai Yang contributed equally to this work and should be considered as co-first authors.
} 
However, the strength data of cortical bone and trabecular bone could not be deduced directly from BMD or trabecular microstructure features. In general, mechanical properties of bone tissue in callus region should also be similar to that of healthy bone (Markel et al., 1990; Suzuki et al., 2020). AFM scanning combined with nanoindentation tests were effective methods in detecting bone remodeling status and mechanical properties of callus at nanoscales.In this study, radius fractures were modeledand then treated with 3 different rehabilitation methods. The bone remodeling status and mechanical propertiesof callus were observed to analyze the promoting effect of PNS on fracture healing.

\section{MATERIAL AND METHOD}

This study procedure was approved by Animal ethics committee of Tianjin institute of medicine science (No. IMPS-EAEP-Z-2019108-01). 12 male New Zealand rabbits (mean weight of $2.5 \mathrm{~kg}$ ) were divided into control group, splintage group and PNS group. All rabbits received radius shaft fracture model construction.In control group, no special fixation was performed on the broken end of the fracture. The wound was bound with splints in splint age group, and PNS was external applied on the surface on wound in PNS group.
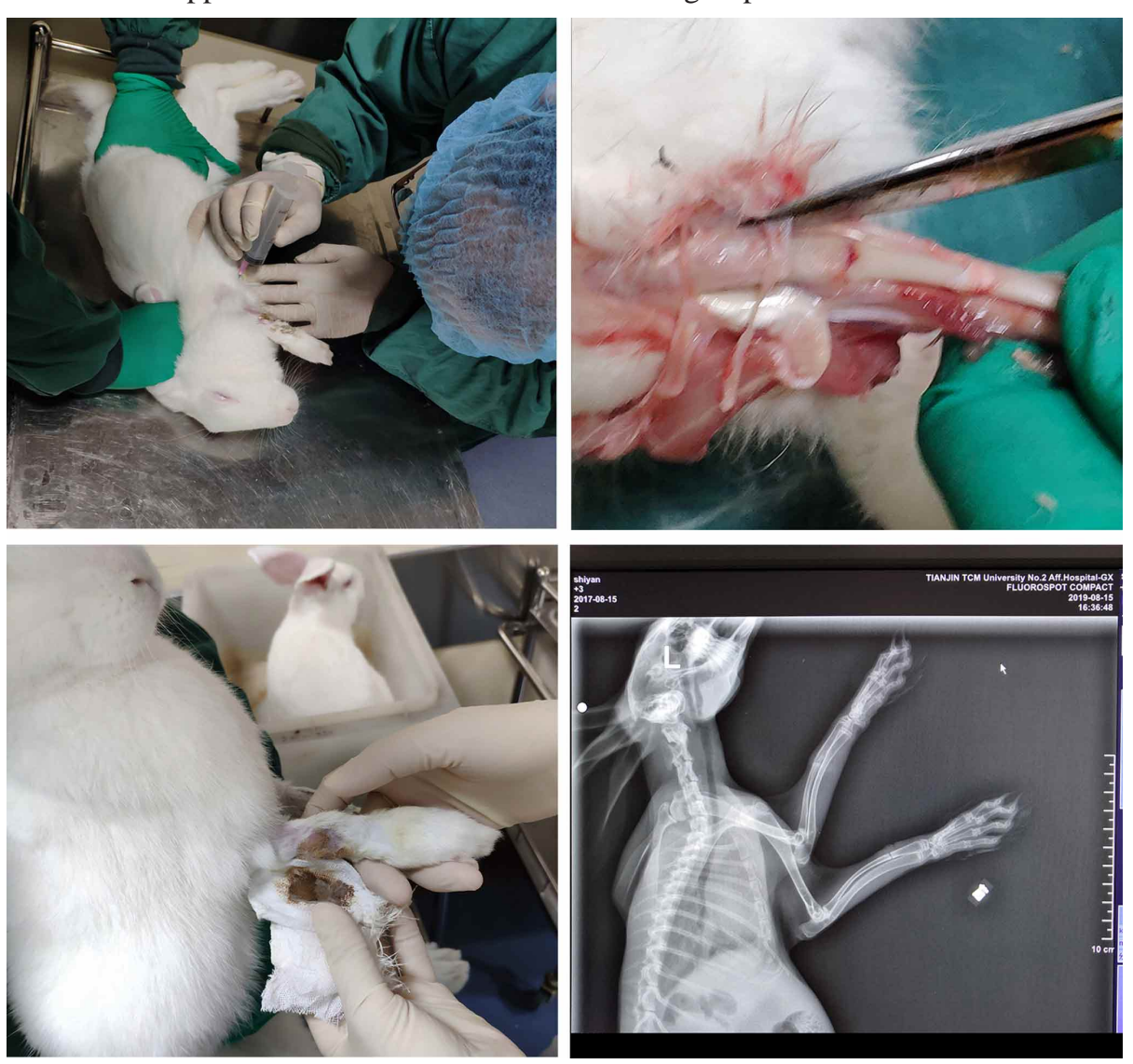

Gentamicin sulfate was injected to prevent wound infection 3 days after surgery with 40,000 U/day. All animals were fed for 42 days after surgery. Two rabbits in each group were randomly selected for euthanasia on day 14, 28 and 42 after surgery. The surgery process was shown in Figure 1.

The callus of radius was cut into two $3 \mathrm{~mm}$ sections along the fracture line and embedded with epoxy resin. During cutting process, the circulating cooling water was always maintained to assist in cooling. After solidification for 24 hours, the embedded slices were polished with 400 , 800,1600 grit sandpaper and silk until the fracture section was just exposed.The images were collected using atomic force microscope probe (RTESPA-300 from Bruker) in standard AFM mode. The scanning mode was Peak Force QNM in Air with scanning rate of $0.4 \mathrm{~Hz}$, peak force amplitude of $150 \mathrm{~nm}$ and aspect ratio of 1.0. The first-order flattening process was performed to flatten the obvious curved or inclined surfaces that appeared in the sample. NanoScope Analysis software was used to measure roughness and particles. Nanoindentation was performed with a nanoindenter TI 950 TriboIndenter equipped with a cube corner diamond Berkovich tip. The sample was indented at 26 ? thermostatic chamber and in dry conditions. Three indents were exerted oneach sample. The indentation was load-controlled at a rate of $100 \mathrm{uN} / \mathrm{s}$ until the maximum force of $1000 \mathrm{uN}$, corresponding to approximately $3 \mathrm{~mm}$ of indentation depth. Then, the tip was maintained for 2 seconds holding time and unloaded at $100 \mathrm{uN} /$ s. A minimal distance of $70 \mathrm{~mm}$ between two indents was set to avoid interaction between indented regions of interest. The bone tissue reduced modulus $\mathrm{Er}$ was calculated from the unloading slope of the load-displacement curves.

Fig. 1. Fracture healing surgery process for rabbits. 


\section{RESULTS}

The bone mineral particle size and roughness of callus in splintage group and PNS group were shown in Table I. The median sizes of bone mineral particles in splintage group were $90.6 \%, 201.5 \%$ and $229.6 \%$ higher than those in
PNS group separately on day 14, 28 and 42 . The bone mineral particle size in subgroup PNS-1 was very similar to that in subgroup splintage-3 after surgery. Roughness in PNS kept around $80 \mathrm{~nm}$ from day 14 to day 42 , while significant variations existed in splintage group from day 14 to 42 . In subgroup splintage-1, the roughness was about 3 times larger than subgroup splintage-3, and finally the roughness in
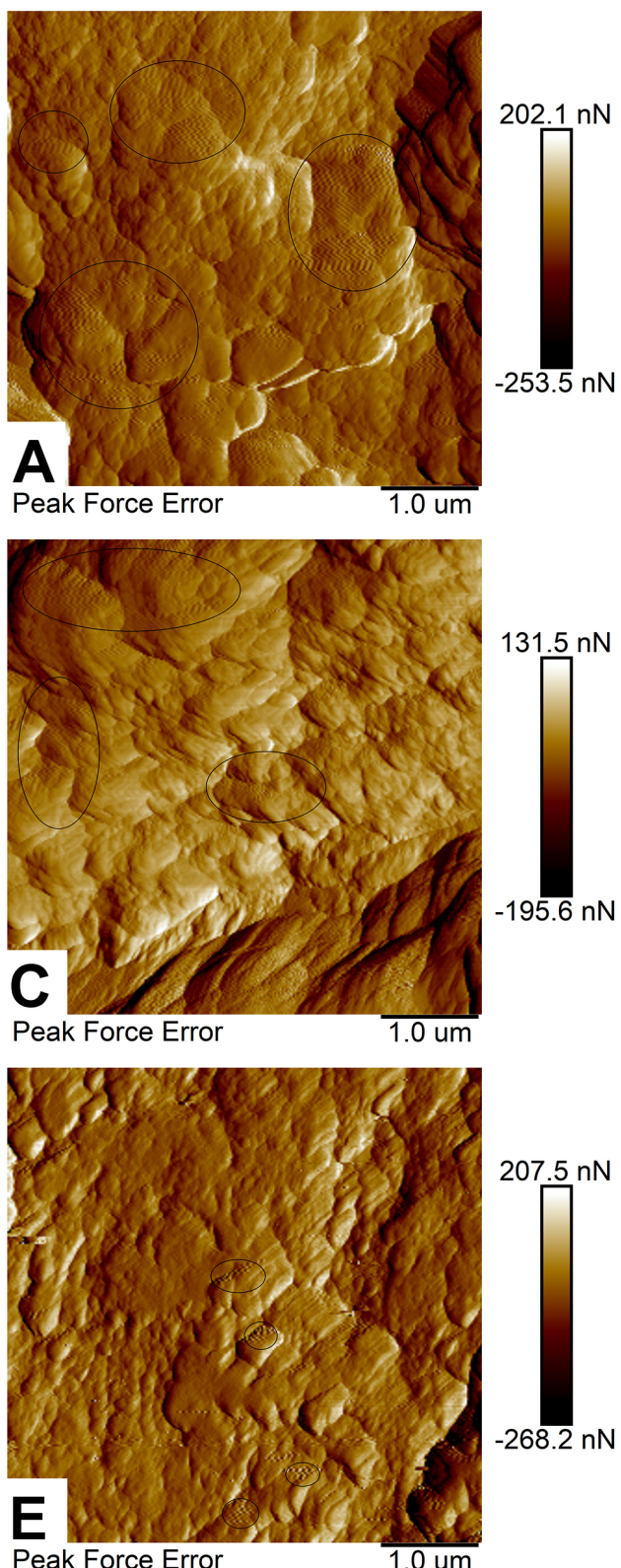
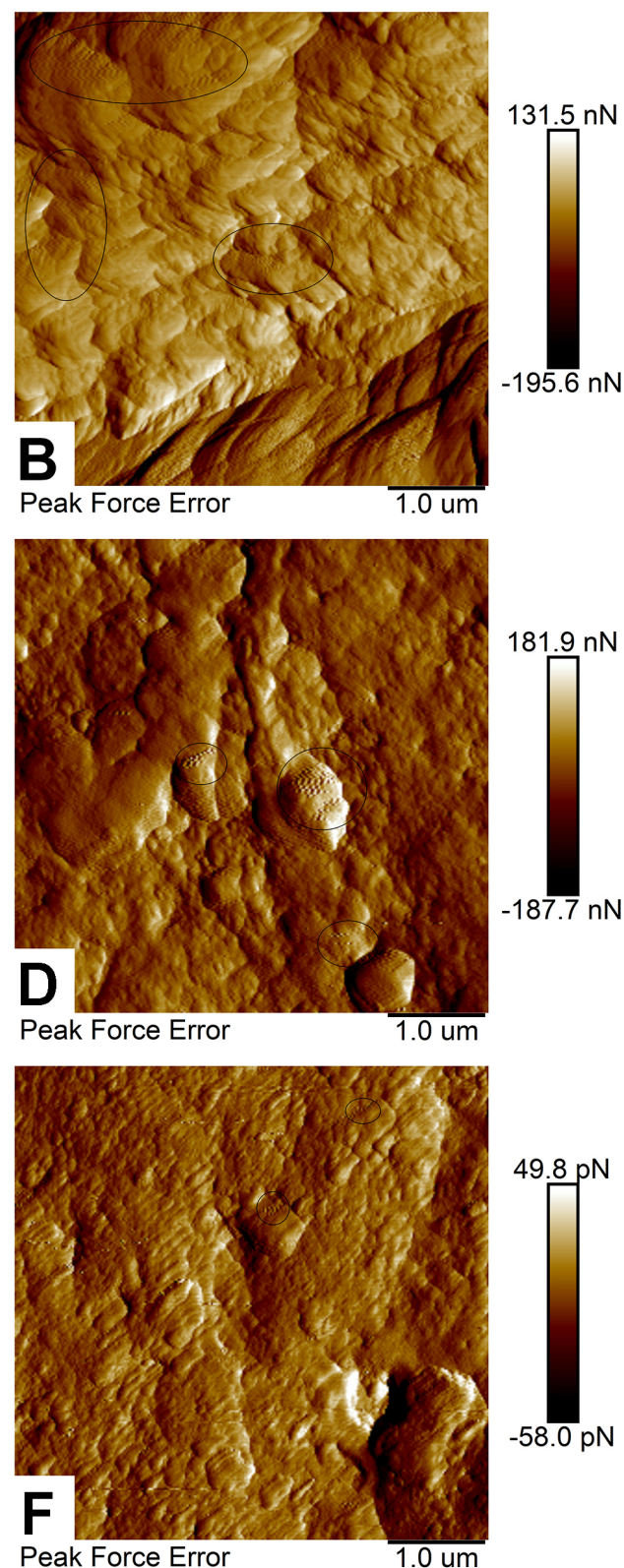

subgroup splintage-3 was consistent with subgroups PNS-2 and PNS-3.

Peak force error graphs in splintage group and PNS group were shown in Figure 2. This was instantaneous error signal of each pixel position, which usually showed finer surface features than height graphs.An oscillating surface topography with a characteristic axial repeat distance of 67 nmwasclearly found, which wasD-period of collagen (Wallace et al., 2012). On day 14 after surgery, there were still a large number of naked collagen fibers in splintage group, while fibers in PNS

Fig. 2. Peek force error in splintage group and PNS group on day 14,28 and 42 after surgery. (a), (b) and ( c) were peek force error in splintage group on day 14,28 and 42, separately; (d), (e) Figure (f) were peek force error in PNS group on day 14 , 28 and 42, separately.

Table I. Mean particle size and roughness of callus in each group (nm).

\begin{tabular}{lcccccc}
\hline & splintage-1 & splintage-2 & splintage-3 & PNS-1 & PNS-2 & PNS -3 \\
\hline particle size & 306.3 & 209.6 & 171.4 & 160.7 & 101.6 & 52 \\
roughness & 302 & 122 & 87.3 & 91.9 & 81.2 & 79.8 \\
\hline
\end{tabular}

Splintage-1: samples in splintage group executed to death on day 14; Splintage-2: samples in splintage group executed to death on day 28; Splintage-3: samples in splintage group executed to death on day 42; PNS-1: samples in PNS group executed to death on day 14; PNS-2: samples in PNS group executed to death on day 28; PNS-3: samples in PNS group executed to death on day 42. 
YANG, C.; YANG, S.; LYU, L.; ZHANG, C. \& SHI, W. Microscopic morphology observation of fracture healing process promoted by Panax Notoginseng Saponins Int. J. Morphol., 39(6):1581-1586, 2021

Table II. Nanoindentation tests for splintage group and PNS group.

\begin{tabular}{|c|c|c|c|c|c|c|c|c|}
\hline \multirow{2}{*}{ Groups } & \multicolumn{4}{|c|}{ reduced modulus $(\mathrm{GPa})$} & \multicolumn{4}{|c|}{ hardness $(\mathrm{GPa})$} \\
\hline & $\mathrm{P} 1$ & $\mathrm{P} 2$ & P3 & Mean \pm Std & $\mathrm{P} 1$ & $\mathrm{P} 2$ & $\mathrm{P} 3$ & Mean \pm Std \\
\hline splintage-1 & 2.78 & 2.38 & 2.00 & $2.39 \pm 0.39$ & 0.09 & 0.10 & 0.09 & $0.09 \pm 0.01$ \\
\hline splintage- 2 & 3.83 & 3.73 & 3.09 & $3.55 \pm 0.40$ & 0.09 & 0.10 & 0.07 & $0.09 \pm 0.01$ \\
\hline splintage-3 & 15.96 & 21.02 & 37.16 & $24.71 \pm 11.07$ & 0.27 & 0.42 & 0.84 & $0.51 \pm 0.30$ \\
\hline PNS-1 & 2.30 & 2.10 & 3.42 & $2.60 \pm 0.71$ & 0.10 & 0.08 & 0.01 & $0.06 \pm 0.05$ \\
\hline PNS-2 & 27.81 & 27.78 & 26.44 & $27.43 \pm 0.78$ & 0.52 & 0.66 & 0.49 & $0.56 \pm 0.09$ \\
\hline PNS-3 & 15.90 & 32.901 & 34.00 & $27.60 \pm 0.78$ & 0.46 & 0.72 & 0.77 & $0.65 \pm 0.17$ \\
\hline
\end{tabular}

group had been mineralized, showing only a few fibers exposed. On day 42 after surgery, only a few fibers exposed in both subgroups splintage-3 and PNS-3. It was concluded that PNS could accelerate collagen fiber mineralization and accelerate fracture healing process.

Nano-indentation data were shown in Table II, Both reduced modulus and hardness on day 14 were in range 2-3 GP a and 0.01-0.1GPa, separately. With the help of PNS, reduced modulus in subgroup PNS-2 was around $27 \mathrm{GPa}$ on day 28 after surgery, significantly higher than that in splintage-2. On day 42 after surgery, reduced modulus in both splintage- 3 and PNS-3 were more than 20GPa.

\section{DISCUSSION}

PNS has been proved to have effects against fracture and osteoporosis (Liu et al., 2016; Wang et al.; Guo et al., 2017). The osteogenesis process stimulated by PNS involved osteoblastic proliferation, differentiation, and mineralization by increasing cellular alkaline phosphatase activity according to oral medicine tests in animals (Ji et al., 2015). In the therapeutic schedule of clinical traditional Chinese medicine, external application of PNS was usually taken as an adjuvant medicine for promoting fracture healing. In this study, AFM scanning and Nanoindentation tests were both performed to observe bone morphological features and mechanical properties at nano level. The results revealed positive effect of PNS in promoting bone healing and improving bone strength.

Milovanvic et al., showed that nano-mechanical properties of bone were significantly dependent on the mineral crystal size, in which the mineral particle size was significantly negatively correlated with the mechanical properties of bone tissue (Milovanovic et al., 2012). In addition, Wagoner Johson and Herschler also found in their study on the synthesis of hydroxyapatite particles that the larger grain size would reduce the material strength (Wallace et al.). It was inferred that from our results that the particle size in both PNS group and splintage group showed a downward trend. On day 42 after surgery, the callus mineral particle size in PNS group was already close to normal healthy bone tissue, and significantly less than that in splintage group. This indicated that the strength of the new bone tissue in PNS group was much higher than that in splintage group, and was close to the healthy state.The fracture surface in all groups healed well according to naked-eye observation. However, the mechanical properties of new bone tissue were close to the healthy state only with the application of PNS according to the AFM data. The mineral particle size in control group and splintage group indicated that the mechanical properties of the new generated bone tissue were poor, therefore, the risk of secondary fracture was more likely to occur.

The callus roughness in PNS group was significantly lower than that in splintage group, indicating that PNS had accelerated the process of bone reconstruction within 14 days after surgery. In addition, there was no significant change in roughness during 28 and 42 days. Bone healing was completed in advance and stable with the help of PNS. However, the roughness in splintage group was significantly higher than that in PNS group, indicating that the fracture area was still not fully healed until 42 days after surgery. Barkarmo et al. (2013) argued that the average cortical bone roughness of healthy white rabbits was $71.7 \mathrm{~nm}$, which represented a stable state of bone remodeling. In this experiment, the callus roughness in splintage-3 and PNS-3 tended to the same level on day 42 , with an average value of $87 \mathrm{~nm}$, slightly higher than that of the healthy state, indicating that the fracture area had basically healed.

It was found from nanoindentation tests that young's modulus of callus in PNS group was about 27GPa. It was concluded that PNS could accelerate osteogenic mineralization. According to Bianchi's results, young's modulus from mature rabbits was $27.7 \mathrm{GPa}$, which was consistent with our data on day 28 and 42 in PNS group. Bone fracture healing period could reduce from 42 days to 
28days. The patients could perform rehabilitation exercise as soon as possible after surgery.

This work had analyzed the mechanism of PNS in promoting fracture healing.However, there were still some limitations during the experiments. First of all, the healing effect of PNS cataplasm on fractures was only limited to qualitative research, and the dosage was about $1 \mathrm{~mm}$ thickness, not strictly determined. Secondly, the sampling points of AFM scanning didn't cover all callus sections. Therefore, the analysis results based on sampling size existed a certain error. The existing limitations will be remedied in future experiments.

In this study, bone graininess and roughness of radius callus were performed contrastive analysis between splintage group and PNS group using AFM scanning and nanoindentation tests, and some conclusions were reached as follows:(1) All fracture surfaces have healed. Naked-eye observation surgical reduction were successful in both splintage group and PNS group; (2) PNS has significant effect in promoting fracture healing. The main clinical manifestations were the reduction of healing time, acceleration of collagen fiber mineralization; (3) PNS improved hardness of callus far higher than splintage group, which could reduce the risk of secondary fracture in callus area.

\section{ACKNOWLEDGEMENTS}

This work was partly supported by Tianjin Administration of Traditional Chinese Medicine (No. 2019082) and National Natural Science Foundation of China (No.12072235).

YANG, C.; YANG, S.; LYU, L.; ZHANG, C. \& SHI, W. Observación microscópica de la morfología del proceso de curación de fracturas promovida por Panax Notoginseng Saponins. Int. J. Morphol., 39(6):1581-1586, 2021.

RESUMEN: El objetivo de este estudio fue evaluar el efecto de la aplicación externa de Panax Notoginseng Saponins (PNS) en fracturas óseas. Se usaron 18 conejos machos de raza Nueva Zelanda divididos en grupos control, entablillado y PNS. Se realizaron fracturas del radio izquierdo y cicatrización natural en todos los animales, además de la cicatrización con entablillado y entablillado recubierto con PNS. Se sacrificaron, posterior a la cirugía, dos conejos de cada grupo los día 14, 28 y 42. Se realizaron pruebas de escaneo con microscopio de fuerza atómica y nanoindentación en las secciones de callos. El tamaño de la partícula y la rugosidad en el grupo de PNS fue menor que en el grupo entablillado. El módulo elástico del callo en el grupo de PNS fue consistente con el tejido óseo normal iniciado el día 28 después de la cirugía, dos semanas antes que en el grupo de entablillado. El PNS podría reducir significativamente el tiempo de curación de la fractura y aumentar la fuerza del callo.

PALABRAS CLAVE: Curación de fracturas corticales; PNS (Panax Notoginseng Saponins); Microscopio de fuerza atómica (AFM); Nanoindentación.

\section{REFERENCES}

Barkarmo, S.; Wennerberg, A.; Hoffman, M.; Kjellin P.; Breding K.; Handa, P. \& Stenport, V. Nano-hydroxyapatite-coated PEEK implants: a pilot study in rabbit bone. J. Biomed. Mater. Res. A, 101(2):465-71, 2013.

Egermann, M.; Schneider, E.; Evans, C. H. \& Baltzer, A. W. The potential of gene therapy for fracture healing in osteoporosis. Osteoporos. Int., 16 Suppl. 2:S120-8, 2005.

Fan, J. Z.; Wang, Y.; Meng, Y.; Li, G. W.; Chang, S. X.; Nian, H. \& Liang, Y. J. Panax notoginseng saponins mitigate ovariectomy-induced bone loss and inhibit marrow adiposity in rats. Menopause, 22(12):1343$50,2015$.

Giannoudis, P. V.; Kanakaris, N. K. \& Tsiridis, E. Principles of internal fixation and selection of implants for periprosthetic femoral fractures. Injury, 38(6):669-87, 2007.

Guo, Y.; Lin, H.; Tang, Y.; Guo, P. \& Zhou, N. Panax notoginseng saponins exert osteogenic promotion effect on rabbit distraction osteogenesis model through TGF- $\beta 1$ signaling pathway. Int. J. Clin. Exp. Pathol., 10(5):6054-63, 2017.

Huang, S. G.; Chen, B.; Zhang Y.; Nie, F. F.; Ju, L.; Li, M. \& Zhang, Y. H. Comparison of the clinical effectiveness of PFNA, PFLCP, and DHS in treatment of unstable intertrochanteric femoral fracture. Am. J. Ther, 24(6):e659-66, 2017.

Ji, Z.; Cheng, Y.; Yuan, P.; Dang, X.; Guo, X. \& Wang, W. Panax notoginseng stimulates alkaline phosphatase activity, collagen synthesis, and mineralization in osteoblastic MC3T3-E1 cells. In Vitro Cell. Dev. Biol. Anim., 51(9):950-7, 2015.

Li, X. D.; Liu, Z. Y.; Chang, B.; Liu, D. X.; Chen, B.; Guo, C.; Wang, Y. G.; Xu, J. K.; Huang, D. Y. \& Du, S. X. Panax notoginseng saponins promote osteogenic differentiation of bone marrow stromal cells through the ERK and P38 MAPK signaling pathways. Cell. Physiol. Biochem., 28(2):367-76, 2011.

Liu, Y.; Lin, Z.; Guo, J.; Xu, G. L.; Li, Y.; Xu, T. T.; Lv, H. Q.; Chen, J. Z. \& Wu, G. Notoginsenoside R1 significantly promotes in vitro osteoblastogenesis. Int. J. Mol. Med., 38(2):537-44, 2016.

Markel, M. D.; Wikenheiser, M. A. \& Chao, E. Y. A study of fracture callus material properties: relationship to the torsional strength of bone. J. Orthop. Res., 8(6):843-50, 1990.

Milovanovic, P.; Djuric, M. \& Rakocevic, Z. Age-dependence of power spectral density and fractal dimension of bone mineralized matrix in atomic force microscope topography images: potential correlates of bone tissue age and bone fragility in female femoral neck trabeculae. J. Anat., 221(5):427-33,2012.

Nalla, R. K.; Kinney, J. H. \& Ritchle, R. O. Mechanistic fracture criteria for the failure of human cortical bone. Nat. Mater., 2(3):164-8, 2014.

Osagie-Clouard, L.; Kaufmann, J.; Blunn, G.; Coathup, M.; Pendegrass, C.; Meeson, R.; Briggs, T. \& Moazen, M. Biomechanics of two 
external fixator devices used in rat femoral fractures. J. Orthop. Res., 37(2):293-8, 2019.

Qiang, H.; Zhang, C.; Shi, Z. B.; Yang, H. Q. \& Wang, K. Z. Protective effects and mechanism of Panax Notoginseng saponins on oxidative stress-induced damage and apoptosis of rabbit bone marrow stromal cells. Chin. J. Integr. Med., 16(6):525-30, 2010.

, three-, and five-year follow-up. Knee, 27(5):1310-24, 2020.

Wallace, J. M. Applications of atomic force microscopy for the assessment of nanoscale morphological and mechanical properties of bone. Bone, 50(1):420-7, 2012.

Wang, Y.; Huang, X.; Tang, Y.; Lin H. \& Zhou, N. Effects of panax notoginseng saponins on the osteogenic differentiation of rabbit bone mesenchymal stem cells through TGF-b1 signaling pathway. BMC Complement. Altern. Med., 16(1):319, 2016.
Corresponding author:

Linwei Lyu

Tianjin University of Technology

Tianjin

CHINA

\section{E-mail: Ivlw@tjut.edu.cn}

Received: 08-08-2021

Accepted: 08-09-2021 